\title{
Samantha Skinner
}

\section{McMaster University, Canada}

\section{Graduate Student Spotlight}

\section{Mothering, Running, and the Renegotiation of Running Identity}

DOI: https://doi.org/10.18778/1733-8077.11.3.03

Abstract Qualitative interviews with six female runners shed light on the gender gap in women's participation in shorter versus longer road races. The interviews reveal that "mother guilt" and "time constraints" play a significant role in the development of a running identity among women. While the running community promotes a discourse centered around a "disembodied" runner-someone totally and unconstrainedly dedicated to running-the participants in this study experienced conflicts between their roles as mothers and their identity as runners. The conflicts led them to engage in challenging the dominant discourse by actively negotiating a mothering and running identity. The findings suggest that women are redefining the boundaries around running and subsequently-running subculture itself.

Keywords Running; Mothering; Running Identity; Mothering Identity; Leisure; Identity

Samantha Skinner is currently completing her MA in Sociology at McMaster University, where her focus is on disability and caregiving across the life course. She is currently working on her MA thesis (supported by the Social Science and Humanities Research Council) on caregiving experiences of primary caregivers of adult children with disabilities. Samantha will be starting her PhD in Sociology at Western University Canada come the fall of 2015. There, she will extend upon her current Master's research and examine more closely how the life course impacts on caring for adult disabled children. Samantha has recently been awarded a Social Sciences and Humanities Research Council Fellowship for her upcoming doctoral studies.

email address: skinnesa@mcmaster.ca be complex and involve many factors, a small, qualitative study I conducted of six women's running experiences generated themes that provide insights and bases for future research. All of the women I interviewed were mothers. My main findings were that the decisions women make about their involvement in running could not be separated from their mothering responsibilities, and that the constraints these responsibilities placed on their running affected, in turn, their identities as runners. More specifically, these mothers found themselves grappling with the dominant discourse of an idealized, "real" runner, or what I call a disembodied runner, someone totally committed to extended hours of training and completely dedicated to improving running skills. Aware of the discourse, but also facing serious limitations in terms of their ability to conform to the image of the disembodied runner, these women responded in one of two ways. While some were willing to relinquish the "runner" identity, others challenged the discourse and redefined for themselves what it means to be a "runner."

In this paper, I look more carefully at these mothers' experiences of running. In addition to considering the constraints they faced, I explore the strategies they used to try to balance and negotiate their mothering roles, their running goals, and their identities as runners. I begin by briefly contextualizing my study in relation to the existing literature on women's experiences with sport and leisure, and road racing more specifically. This is followed by a discussion of the methods I used to conduct my study. My findings are organized around three main themes-"running identity," participants' experiences of "mother guilt," and the "time constraints" that acted as barriers to running. I also address women's responses. Lastly, I consider the implications of my findings for the running subculture.

\section{Conceptual Framework}

Conceptually, there were two areas of sociological debate that informed my analysis and oriented the discussion of my findings-first, the concept of boundaries, and second, the literature on identities. A boundary can be understood as an area where something ends and something else begins. Wimmer (2008) defines a boundary in two ways; socially and categorically. Boundaries are used to categorize groups through social classification and social representation. The social dimension of a boundary is established through interactions and acts of connecting oneself to, or distancing oneself from, such categories. A social boundary is "when ways of seeing the world correspond to ways of acting in the world" (Wimmer 2008:975). Boundaries are unique in that they can draw clear lines of distinction, or be "soft and fuzzy" (Wimmer 2008:975)

Lamont and Molnár (2002:167) describe social boundaries as "objectified forms of social differences manifested in unequal access to and unequal distribution of resources (material and nonmaterial) and social opportunities." In relation to the running community, for example, social boundaries establish who is able to participate in, or be accepted by, the community. How and where boundaries are drawn clearly has implications for 
the identities that social actors are able to adopt. Identities are components of the self that are created by interacting with other social actors (Appiah 2001; Vryan, Adler, and Adler 2003; Collinson and Hockey 2007). An identity is articulated through conceptions (and practices) made available by religion, society, school, and states; and mediated by family, peers, and friends.

Appiah (2001) conceptualized identity as having two dimensions: the collective and personal. The collective aspect involves the intersections of identities (ethnicity, sexuality) that create a kind, or category, of person and which are realized by the attributions others make in terms of who we arean employee, mother, or a runner. The personal dimensions of identity are the features that are socially important, like intelligence, charm, and greed, but are not the basis for forming a collective identity. The labels of a collective identity (e.g., runner) are the descriptive criteria, which lead to expectations about how individuals possessing that label will behave (Appiah 2001). Therefore, there are conceptions of how one possessing a given label should act, and consequences in terms of how that person is treated based on their ability to perform the acts connected with that label.

Furthermore, identity provides a source of values for people. To adopt an identity is to make it one's own, often necessitating a restructuring of one's life to fit the values associated with the identity (Appiah 2001; Vryan et al. 2003). Certain values are integral to identity; therefore, for those who aspire to that identity, take on the values congruent with that label. Similar ideas concerning identity have been found in running subculture research discussed below.

\section{Literature Review}

There is a growing body of literature on the subculture of running. Altheide and Pfuhl (1980) found that runners have a high commitment level termed a "running career" which requires a dramatic reorganization of other activities in their lives so as to allow for the time it takes to train and keep the body in shape to run longer distances. The running subculture distinguishes between "runners" and "fun runners" or "joggers." Smith's (1998) participants made a clear distinction between running and jogging, and disliked being referred to as joggers. Joggers tend not to train on a regular basis, run only when weather permits, and do not prioritize running in races. Runners, on the other hand, are committed to training, running greater distances, participating in races, and running at higher speeds and race paces. Further, Ogles and Masters (2003:70) concluded that although runners are a heterogeneous group, running and training for marathons, in particular, require training which "necessitates that work, meals, family, and social schedules be organized to accommodate the regime [of running]." Therefore, time with family and friends is often reduced if one wants to be a "real" runner. Here, the subculture is establishing a clear distinction or boundary between different types of runners. Using these boundaries, they have created a hierarchy with "runner" situated at the top, according to Smith's (1998) participants, and "fun runner" or "jogger" towards the bottom. Such a hierarchy of runners creates boundaries around the running identity and places restrictions around who can lay claim to that identity.

Turning to the literature on mothering, research by Heisler and Butler-Ellis (2008) concluded that women receive messages from peers, family, and media about how to be a good mother. These messages promote putting the interests of their children first, because motherhood is understood as the most important and consuming part of a woman's life. Other desirable traits of a mother include being patient and always present. Griffith and Smith (2005) argue that the mothering discourse is prevalent and strongly influences the way a woman should be and feel about being a mother. As such, mothers feel pressured to conform to certain expectations of motherhood, where "mother" becomes their master status. As a master status, this identity becomes central to women's identity and one from which it is difficult to stray (West and Zimmerman 2007). As a result, other roles-wife, employee, and, in this case, runner-conflict with the resources a woman has to dedicate to being a mother. The responsibilities of being a mother affect the amount of leisure time available to women.

Leisure can be a positive experience for women. Kay (2003:5) argues that personal leisure is a "crucial area of experience for the (re)assertion of a sense of self-identity that the demands of paid work and family responsibilities may otherwise overwhelm." Moreover, leisure helps women to challenge traditional gender relations, find ways to maintain selfcare, and bring balance to their lives. Therefore, running as leisure can provide positive benefits to women in terms of creating a self-identity.
Paid and unpaid workloads affect the leisure time available to women. Leisure time is defined as the time left, "after the time spent in market and non-market work and meeting physiological needs (sleeping, eating, attending to personal hygiene, and grooming) is deducted" (Bittman 2004:154). Bittman (1998) and Gershuny (2000) argue that leisure time for men and women has increased over the last three decades. Yet, despite this increase in leisure time, many women still feel a "time crunch" (Bittman 2004; Bittman and Wajcman 2004; Mattingly and Sayer 2006; Gimenez-Nadal and Sevilla-Sanz 2011).

There continues to be a greater lack of free time for mothers compared to fathers (Sayer 2005; Mattingly and Sayer 2006). Mothers who work full-time, have a partner that works full-time, and have children under the age of 15 suffer the most from leisure time poverty (Bittman 2004). Overall, women have a significantly lower average of weekly hours dedicated to leisure activities (Bittman and Wajcman 2004). Women's leisure is more likely to be interrupted, occur in smaller increments, and be associated with unpaid work than for men (Bittman and Wajcman 2004). Men on average have a higher quality of leisure time than women (Mattingly and Bianchi 2003; Bittman and Wajcman 2004), and benefit more from leisure time than women (Mattingly and Bianchi 2003; Mattingly and Sayer 2006).

There are gaps in the research pertaining to women, leisure, and running. Little research focuses on identity formation of runners. The majority of research on running focuses on elite male runners under the age of 30 (Collinson and Hockey 2007). Feminist 
researchers tend to have focused most of their attention on understanding how women have become involved in sports in general (Jutel 2003; Patel and O'Neill 2007), and how sport and running oppress women (Choi 2000; Dowling 2000; Abbas 2004). Further, there is a paucity of research on how running as leisure can act as a site for identity formation, particularly that of a running identity, and how this may impact race distance choices of women, particularly mothers. Lastly, more research is needed focusing on the experiences of female runners who are non-elite and middle-aged. The findings of this study contribute to these areas.

\section{Methods}

As part of an undergraduate thesis, I conducted interviews with six women involved in running. I specifically targeted women who were accomplished runners within their community (having completed at least one race), worked at paid employment, and had children under the age of 15 . I established these criteria because I was interested in how women work running into other responsibilities they have in their lives. In recruiting participants, I used both purposive and snowball sampling. Berg (2009) points out that these methods are an effective way to gain contact with specific populations that one wishes to target. As part of a running community myself, I drew on contacts I had within the community to initiate recruitment. I started by requesting an interview with a fellow runner, Janet. ${ }^{1}$ Janet put me in touch with five other runners willing to participate.

${ }^{1}$ All names have been changed to maintain confidentiality.
I conducted semi-structured interviews with the participants, which lasted between 45-90 minutes. I audio-recorded each interview for accuracy with the knowledge and consent of the participants. My goal through the interviewing process was to create a conversational atmosphere rather than a formal interview. A naturalistic interviewing style generates richer, more diverse, and more complex responses from participants (Berg 2009; Lynch 2010). I made references to my own running experience, used humor, and asked questions that showed a general interest in participants.

During these interviews, I had both an insider and an outsider status. An "insider" is defined by Kanuha (2000) as someone who is part of the same population as the participants and may also share the same identity, language, or experience. As a runner myself I was an insider, which helped me to establish rapport with my participants. But, being an insider has its drawbacks. Corbin-Dwyer and Buckle (2009) point out that participants might make assumptions of similarity and not be clear on their experiences when being interviewed by an insider. I found this to be the case when, as a less experienced runner, I had to ask participants for clarification with respect to running terminology they used and race references they made. At the same time, I did not share with them the experience of being a mother or having full-time work responsibilities. My outsider status with respect to these experiences allowed me to pick up on points I might have missed had the interviews focused only on common experiences.

Of the six participants, five had at least one child between the ages of 5 months and 15 years of age.
The sixth participant, Janet, has no children under the age of 15, but a 26-year-old child with disability who requires full-time care. I chose to keep Janet in the study even though she did not strictly meet the recruitment criteria because the time and effort that her caregiving responsibilities require make her comparable in many respects to other participants. Five of the participants worked full-time at the time of the interviews.

The length of time the participants had been involved in running ranged from 3 to 13 years. Each runner had completed at least one race. All had completed races of distances between 5 to 10 kilometers. Five of the participants had completed at least one half marathon, four had completed a local thirty kilometer race, and three had completed at least one marathon, with one having completed ten marathons. At the time of the interviews, all were training for a race that would take place between March and May of 2013. I sought women who had different levels of road race experience in order to get at various running experiences.

The interviews ranged over several topics. I inquired about how much running experience participants had, the types of races they preferred, training programs, and time spent running per week. I asked how much time they devoted to caregiving, what tasks their caregiving responsibilities included, and how they worked running into their days. I engaged them in discussions about their leisure time more generally and decisions they made about how to use this time. To capture their thoughts in relation to their identity as runners, I asked whether they defined themselves as run- ners and how they understood what it meant to be a runner.

In analyzing my data, I took a thematic approach. I used open coding to code my data. Open coding involves deconstructing or segmenting the data into fragments that are then compared to each other and grouped into categories revolving around the same subject (Boeije 2010). I methodically went through verbatim transcriptions of the interviews, coding segments of the data in terms of what was being said and the significance of those statements. This allowed me to create categories I then grouped together with related categories to indicate the specific properties of the data (Boeije 2010). Guided by my research questions, I identified three major themes that ran across the interviews-"running identity," "mother guilt," and "time constraints." These are the themes around which I have organized my analysis.

\section{Analysis}

Three main themes emerged out of the analysis of my data, the most prominent being running. Participants identify what being a runner means to them, indicating the clear boundaries that exist around types of running identities. Running identity is, in turn, affected by mother guilt and time constraints. Both being a runner and being a mother make great demands on one's time and resources, limiting temporal availability for other pursuits. My interviews show that participating in running poses challenges to my participants' mothering identity, which leads to "mother guilt." It is here that the boundaries between running and being a mother are in tension, 
which affects participants' running identity. Time constrains also affect running identity as the time it takes to run and train exceeds the time participants have available in their schedules for leisure activity. As a consequence, some participants renegotiated their understanding of the running identity in ways that fit their own lifestyles. They challenged the boundaries around the running identity, being a "real" runner, and created a new running identity.

\section{Running Identity}

Identity is developed through interactions with others. Adopting an identity means conforming to the roles that are associated with that identity. For the running subculture, this means being a "career runner" or a "runner" and not a "fun runner" or a "jogger." Running becomes a commitment that requires time and dedication

There are clear boundaries around the running subculture and community. Being a "real" runner has specific requirements including the amount of training, speed, and dedication. Feeling like a "real" runner, or having the identity of a runner, is a part of the boundaries of the running community as it is either confirmed or denied based on interactions with other runners. Boundaries exist at both the categorical level and social level. At the categorical level, a "real" runner is a type of person, a category that has been created and socially agreed upon based on mainstream images of runners and interactions within the running community itself. The categorical representation of a runner and the social interactions that reinforce or undermine one's identity as a runner are what I call a disembodied runner.
I have derived the concept of disembodied runner from Joan Acker's (1990) "disembodied worker." Acker (1990) contends that many workplaces require a worker to have no outside commitments, with full dedication to their work. As a result, a disembodied worker ideally "cannot have other imperatives of existence that impinge upon the job. Too many obligations outside the boundaries of the job would make a worker unsuited for the position" (Acker 1990:149). Due to the traditional division of labor still prevalent within Western society, men are, in fact, the disembodied worker, while women maintain the private world of the household, children, and community, thereby leaving men the freedom to participate in the public sphere.

A disembodied runner is similar to a disembodied worker in the sense that being a runner requires the majority of one's time and dedication with few outside distractions. Margaret describes a runner and highlights the criteria of a disembodied runner: "A definition of a runner would be someone who definitely dedicates their life to mainly running, and nothing else. Not gyms, not circuit training, I just picture them out there running all the time." Another example of a disembodied runner is evident in media and advertising like Nike's "Just Do It" slogan, emphasizing that one should be able to accomplish one's goal, with no exceptions or excuses.

Having the opportunity to run without constraints or restrictions is not something that all runners can do, particularly mothers. One cannot always commit to the rigorous schedules of running. For mothers, life consistently gets in the way of running. As
I will show, my participants must constantly renegotiate their time in order to accommodate all of their responsibilities and their running goals. This work of renegotiation may not be recognized within the larger running discourse. Instead, there is a conception that women, if they are truly dedicated to running, should "just do it." I now turn to two themes that make being a disembodied runner difficult for mothers.

\section{Mother Guilt}

Griffith and Smith (2005) argue that a mothering discourse does not take into account the amount of resources needed to raise a child, such as the time and energy involved in caring for children. As a consequence, this discourse creates an "exposure to guilt, individual comparisons, and anxiety [which] all are constant hazards for mothers participating in the discourse" (Griffith and Smith 2005:39). As a result, even though making time to run, for example, is good for these participants physically and mentally (Choi 2000; Kay 2003), it defies the standard ideological framework of "mothering." Therefore, running conflicts with what it means to be a good mother. Boundaries around motherhood promote selflessness and spending the majority of one's resources (e.g., time, money, energy) on the child. These boundaries limit the types of activities mothers can do on their own without being framed as selfish or "bad" mothers. Such boundaries, and the resulting mothering discourse, deter some women from committing the extended hours needed to train as a "real" runner. Moria was the only participant who had not run in a half marathon. As a moth- er with three young children her time was constrained:

I wish I could run more. I think I would achieve my goals faster if I had more time ... I would love to get to a half marathon probably by the end of 2013. And then take it from there, but we'll have to see ... there's 24 hours in a day, but there is always something that needs to be done, and when you are always putting yourself last, that can get difficult.

Some of the participants felt conflicted about the amount of time their running takes and the time spent away from their children. Moria joked that her running was "pure selfishness," despite the fact this is the only time she takes for herself. Carrie described the conflict she experienced between her running and being a mother as "mother guilt," and claimed that this conflict figured prominently in the decision she faced about whether to train for another marathon:

[After discussing if she will do the Toledo half marathon or full marathon race]

Me: Are you concerned about the time constraint over training for a marathon versus a half marathon? Carrie: Yes, that would be the biggest thing. Um, it's not that I don't think physically and mentally I could do it, because I know I just did it ... It's more that extra, um

... I find Saturday mornings, if I didn't have children at home, no problem I'd be running a marathon every, twice a year. Um, but it's that extra seven, eight kilometers that takes another hour, two hours, depending of your Saturday, and mother guilt starts setting in.

For Carrie, not spending enough time with her kids was a challenge. The time it takes to run long 
distances, despite her love for the activity, conflicted with her role of being a "good" mother.

Moria shared similar sentiments to Carrie about not wanting running to interfere with mothering. She stated that she wished she could run more, and have time to dedicate to training. A gendered notion of what it means for her as a mother to take care of her children conflicts with the wish to run more:

... I don't want to miss out on the younger age's groups, um ... I am more the caregiver. I wipe the noses, I make the lunches, and I set up the doctor's appointments ... Um, so if I want all the little details accomplished so that the household can run, so to speak, then I need to be the one to do it.

As evidenced by her last comment, being in charge of scheduling time and making all of her commitments fit was important for Moria. Although Moria was the only participant who explicitly stated that she was the only one in the family who could balance the schedule and run the household, all participants expressed the importance of time management in order to balance their running, family responsibilities, and work.

Though most participants did not explicitly discuss their experiences in terms of gendered inequalities in their childcare and domestic responsibilities, it was clear there remains a gendered dimension to their running, and more specifically, their running goals. Women are almost always identified as the sole or primary caregiver of children. Women are socialized to be a specific type of mother, as stated above. This conception of a mother can conflict with women's other roles or identities. In some cases, it may prevent women from dedicating their time to other interests, as seen with the participants who are hesitant to commit the extended amount of hours needed to complete a marathon.

The experience of mother guilt among the participants is an expression of the broader problem of gender inequality within the context of leisure and sports. Running was important to the participants, but not as important as their domestic responsibilities. If it was as important, then in many cases, the participants had difficulty finding time to engage in a satisfying amount of running. This is not only a barrier in terms of juggling being a "good mom" with being a runner, but such gendered issues also affect women's ability to compete, or perception of their ability to compete in longer distance races. Carrie states:

We [her running group] are going to do Toledo. Some are doing the half and some are doing the full. Sometimes, I don't go on very many of those [races out of town] 'cause it is a weekend away from the family ... I don't want to take a weekend away from the family to do a run. You know? I love running, but while the kids are really little it's more important for me to be home, whereas my husband, he loves running like he loves it as well, but he is so dedicated to his training schedule with his marathon group that he, it's well worth it to take a weekend away from the family to go and do his race.

For Carrie, it was not worthwhile to leave her children for a weekend because she was "less" dedicated to running than her husband. It may not be that she is less dedicated, Carrie has run a marathon, rather, she felt like less of a "real" runner because she finds it harder to balance her running with domestic responsibilities. Beyond mother guilt, but not fully unrelated, are the time constraints that can make running difficult.

\section{Time Constraints}

As discussed in the literature review, women who are married and have children have the least amount of leisure time (Bittman 2004). This theme came through in my interviews with participants. For Moria, the barrier to longer road races is clear, time is not on her side. For her, the maximum amount of time to run per week was four hours, a small amount compared to participants like Janet and Kathy who trained eight to ten hours a week for a marathon. This lack of time for training is not a unique experience; all participants wished they had more time to run. Time, then, is a distinct barrier.

In addition to the lack of time available to compete in longer races, not having time to train for longer distances can affect one's identity as a runner. This is true if the boundaries around being a "real" runner require the individual to accomplish a certain mileage a week in order to meet their goals.

The training program that I had was given to me through one of the running groups and, um, I think their methodology is run more. So, I did, and felt that I had to or otherwise I just wouldn't be prepared for the marathon. Um, but I think realistically it really isn't suited to the average person. And so, I, even though I had already been running for a few years, it was still too much. (Kathy)

These standards for what it means to be a "runner" may impact one's desire to do a marathon if they do not feel that they can accomplish being a "real" runner. Moreover, it may impact whether one perceives oneself as capable of doing a marathon. When full marathons came up in interviews, there were mixed responses. Theresa has no desire to run a marathon and was happy running a local 30k road race and half marathons:

I have never done a marathon ... It just does not interest me ... Um, I think actually because of the amount of training time it takes for me. Especially when working ... And I, for me, yeah, it's just a matter of time. 'Cause I know how much time, I mean the long runs take up a lot of your Saturday, and plus you are exhausted for the rest of your Saturday. And then your other runs also need to be longer, it's not just a 30-minute run a couple times a week. It's another hour run and then another 45-minute run, you know, so. For me, I've just found I am not willing to commit the time.

Similarly, the other two participants who had not run a marathon identified time as the chief constraint. Even for participants who had completed marathons, there was hesitation about committing to marathons in the future. Janet, who was 57 at the time of the interview, had completed over ten marathons, including three Boston Marathons, but was hesitant to fully commit to another one:

... if I run a marathon again, I have no desire to get any longer than four and a half hours. I probably won't 
ever run if I think I'm going to do a five hour marathon ... Too long ... it's hard enough to get through, well, it's boring, but it's just you're forcing yourself to ... I liked it better when I could run it under four hours, and maybe if I worked my tail off, I could do that again ... I'd have to be really [fit], and I physically don't know if I can. Like when you get older, you just can't necessarily. I'm not a natural born runner.

In this instance, time is an important factor, but for a different reason. Time becomes an issue in terms of speed. For Janet, taking too long to finish a race takes the joy out of it. Similarly, Margaret expressed this sentiment after she described the completion of her first half marathon. She said that after taking nearly two and a half hours to complete a half marathon, she had no desire to try a marathon.

Time availability for these women is a palpable constraint that prevents them from participating in the ideal amount of training necessary to be a disembodied runner. For these women, whose lives are spread thin with their familial and work commitments, time is relentlessly ticking away. When asked about leisure time, Margaret, Moria, and Kathy said that the only leisure time they had for themselves was when they run; and for Janet, Theresa, and Carrie, who said they have additional leisure time, half of that leisure time or more is spent on running.

For all participants, time was central to making, working towards, and accomplishing their running goals. When asked the question "What would you say is the biggest barrier to your running?" participants clearly stated it was time:
Time, there's 24 hours in a day, but there is always something that needs to be done, and when you are always putting yourself last, that can get difficult. (Moria)

Not enough hours in a day ... Three kids and a husband, full-time job ... you know there are expectations bigger than myself on me with ... So yeah, I think, just the time kind of gets allotted to so many different things, and there are so many expectations on my time ... so, um, yeah. I'd say it's time. (Theresa)

Most participants believed that running is great because it is one of the only forms of exercise that they are able to fit into their schedule. Ironically, all believed they did not have enough time to run, and must carefully manage their time in order to do so. Griffith and Smith (2005) recognize time management as an essential part of the mothering discourse. However, efforts for such time management often go unnoticed. The time it takes to manage time is usually not recognized as work itself, because it is considered part of women's domestic responsibilities (Griffith and Smith 2005). Time managing their families' lives becomes an important part of running as it requires allocating the right amount of training time for specific running goals. Having to allocate time to time manage is also not part of the running culture, or being a disembodied runner. Being a disembodied runner assumes the successful management of those responsibilities.

Importantly, leisure remains a crucial site for both men and women as a way of asserting their sense of self-identity, where the demands of paid work and family responsibilities have the potential to overwhelm (Kay 2003). Women find it challenging to carve out guilt-free leisure time. Similar to the issues of mother guilt, women struggle to persuade themselves to feel a sense of entitlement to leisure time because they tend to prioritize others' needs over their own.

Additionally, Kay (2003) concluded that when women do secure leisure time, they do it in less direct ways. In order to feel like they are not "on duty," women tend to participate in leisure that is removed from their home and family. Joining running groups is one way for women to remove themselves from the home. Their respective running groups have allowed them to set in stone their running time-their leisure-without feeling the guilt or pressure to change it for others. Though these group runs are "rarely missed," most participants said they have to get creative when it comes to scheduling the rest of their runs each week. In some cases, runs which were not part of a group run were not completed.

It is clear that the biggest barrier to women's running is time. All of the participants feel that they do not have enough time to train, wish they could train more, and-ironically-have to spend considerable time managing and organizing their time. Time management becomes an essential asset to the participants' attaining running goals. Literature on women and sports seem to overlook the importance of time management. The time constraints, the struggles these participants face in terms of meeting their running goals, are a part of a larger gendered society that still unloads a sec- ond shift onto women, leaving them with less leisure time and a higher requirement to time manage (Hochschild and Machung 1989).

\section{Renegotiation of Running Identity}

Part of establishing a running identity is conforming to the roles and social boundaries attached to that identity (Appiah 2001; Vryan et al. 2003). If those cannot be met, it is logical to assume that identity may not be taken on. I found this with my participants. If the participants cannot hold both running and mothering identities in the way demanded by the running subculture, they are put in a position where they must prioritize one or the other. It is clear from the interviews that the mothering identity takes precedence and is less subject to accommodations. All participants felt strongly that family comes first. The other option, then, is to adapt and renegotiate their running identity. In discussing their understandings of what it means to be a runner, three of the participants felt uncomfortable calling themselves a runner. Moreover, there appeared to be no real consensus on what it meant to be a runner. The majority of their definitions of "runner" did not fit the typification of the running identity in the discourse that characterizes the running subculture.

As Appiah (2001) suggests, if one is to conform to a given identity, they must embody the values of that identity. Part of the identity process is to conform to the boundaries that surround the symbolic category of a disembodied runner. In this case, these women cannot, so their alternative is to create a running identity with established values 
that fit their sense of self and are compatible with their mothering. As a result, participants have created definitions of a "runner" that best suited their needs, lifestyle, and commitment to running. Some participants defined running identity as follows:

Um, I would say, I would say, yeah, it's something about a love of the sport. 'Cause I think there are exrunners too, there are maybe people who can't run anymore because of whatever circumstances or physical, but I think there's a, yeah, there's a certain element of craziness [laughs]. (Kathy)

It's, it's, you know, a person who runs on a regular basis, you know, a certain amount of distance regardless of time, um, that's dedicated to, you know, doing a few races and, you know, kind of getting out there as much as possible. I guess I am a runner, I just never really call myself a runner. (Theresa)

Someone, motivated, for health reasons and enjoyment, who gets up off their butt and goes for a run consistently. You know, it's not enough to do it once a month ... Um, you need to keep at it because you are not going to get any better if you are not consistent with it. (Moria)

Creating a running discourse different from the dominant discourse requires active contestation of the disembodied runner and a realization such a definition of a runner is not the only option. Through their construction of an alternate definition of a runner, participants are challenging the boundaries created by the dominant discourse. Wimmer (2008:995) notes that in ethnic groups, subordinate members may choose counter discourses and other ways of "dividing the social world into groups than those propagated by the dominant actors." Similarly, participants in this study actively challenge the boundaries surrounding a "real" runner and, by extension, the category of runner itself. Janet describes her experience at a local competitive running group and gives an example of the disembodied runner:

... running was their life. Like some of them have gone on to do Iron Man and stuff, too, but they do the six times a week running, or if they are really runners, they do the program called pfitzinger and it's like 90 to 120 miles a week 6 days a week. Sometimes they are running twice a day.

Janet, however, has actively been able to contest the social boundaries of a runner and has developed her own running discourse; one that fits her running experience. In reference to the competitive runners making it to the Boston Marathon, Janet stated:

And yet, I've got to the Boston Marathon before some of them. Running, three times a week, run less, run faster. It's just, it's a real mental, I'm glad I hang with people I do [that don't focus on time and competition] and think more like that because I don't know what I'd do if I had to hang with people that felt, and felt the pressure to do a pfitzinger program 6 days a week running. I know I'd hate it. I would not want to run if I had to make myself run 6 times a week. No all those people, all my group are runners, they run regularly three or four times a week and that's their main choice of physical fitness. They are runners.
Janet has chosen to view running in a different way. Running, for her, is not about competitiveness but rather about doing it consistently and choosing it as a main form of exercise. She applies this definition to herself but also to those in her running group. Janet's ability to successfully renegotiate what being a runner is has helped her to construct and maintain a running identity for herself.

Um, I mean, it's interesting 'cause everybody who knows you run asks you if you are still running, or about your running. For me, 'cause I don't have like another "job," a paid job, that's my identity with people. It's weird. Do your people ask you if you're still doing yoga? Are you still going to Goodlife? You know [laughs] kind of do a bit, but running is a funny thing. Even if they are not runners at all. So it's kind of a sense of identity I guess and a sense of accomplishment that I can do that.

Some of these participants, despite defining a runner in ways that challenge the dominant running discourse, still do not feel like a "runner." Theresa recognizes that she fits her own definition of a runner, but struggles to say, "I am a runner." Carrie also realizes that she, by her own definition, is in fact a runner, but feels a runner should perform with ease and grace, and be thin, which she does not consider herself to embody. The struggle for both of these participants to call themselves a runner indicates that self-defined categorical identities can be difficult to sustain.

In some instances, these participants choose not to commit themselves to the running identity and say, "I run" instead of "I am a runner." This speaks to the influence the dominant running discourse has on women who run. Margaret and Carrie explain why they choose to say, "I run" instead of "I am a runner":

Um, just because I'm not one that goes the distances. I always think these little ones [races] are just things people do because they want to stay healthy and whatever. I think, I look at someone like Janet and who, to me she is a runner. She is my motivator. She's the one that got me kind of thinking, "Oh, I can do this, too." I just don't want to do it with her [laughter from both]. She goes too far! (Margaret)

... no, I mean, I know I'm a runner and I have medals and I run, you know, three times a week and do long runs. I don't, I don't know. I guess 'cause my physique is not like a, you think of a runner and you think of someone like, not so, not so big like just a small, um ... I look through Runners World magazines and I think now those people are runners ... But, not me, you know? ... I don't know. I think for me it's probably, you know, it's just, um, a stigma out there like a social thing, like you have to have a certain physique to really be a runner. Which is not true 'cause if I look at all those people that are running in races beside me, ahead of me, behind me and out on Saturdays we all look different ... and I know I am a runner, like how can you run a marathon, how can you run for 5 hours and 28 minutes and not call yourself a runner. It's not possible. (Carrie)

Carrie takes pride in her running accomplishments, but struggles with calling herself a runner, despite her significant accomplishments. Margaret looks to the other participant, Janet, and believes her to be 
more of a "runner," despite Margaret's own running accomplishments. Margaret also refrains from calling herself a runner because she mostly does shorter distances. It may be that Margaret views herself as more of a "fun runner" or "jogger," as described by Smith (1998).

Additionally, one may refrain from using the term "runner" for fear of not being able to conform to that identity, and being recognized by the running community as a "fake." Saying "I run" instead of "I am a runner" removes the responsibility and expectations of being a runner. McLuhan and colleagues (2014) have recently found individuals can take on a cloak of incompetence, that is, present themselves to others as inept or less than capable in some way, as a way of managing others' expectations. For example, in some situations, those with disabilities may choose to highlight those disabilities rather than hide them as a way of signaling what they can and cannot do. Or, a stutterer may make an obvious show of their stuttering at the beginning of a conversation so as not to set up expectations of verbal fluency they would not be able to meet. In terms of running, by avoiding the label of runner and saying simply "I run," my participants are effectively taking themselves out of the "disembodied runner" category. Outsiders and those within the running subculture will not expect the participants to be as fast, fit, or dedicated to running. This allows the participants to avoid feeling like a "fake" and manage any sort of disappointment or rejection from the running community. An example of this fear could be seen by Kathy who despite being an experienced runner worried about being judged in her new running group. If
Kathy used the disclaimer of "I am not a runner," she may not have been so anxious about other runners judging her.

External validation from peers outside of the running community may not be enough to convince the participant that she is a runner. This point was illustrated by Theresa who did not call herself a runner even after recognizing that her colleagues and family do. The most important validity may come from their running community itself. As shown by Shipway, Holloway, and Jones (2012), the running community is an important site for identity formation. It is central to running experience and developing a running identity. The running group can provide rewarding experiences for runners (Shipway et al. 2012), however, if one does not feel like a runner or is uncomfortable within the running group, those experiences may not be positive. Carrie explains an experience with her husband's running group, where she felt uncomfortable on the bus when all the men were comparing race times.

For Around the Bay [local race] there's a bus of people that go to the race and I sat on my husband's bus ... I sat beside a guy who ran Around the Bay, 30k in an hour and fifty something minutes, and I ran it in 3 hours and 38 minutes. I was almost embarrassed to tell my time right? [Laughs]. And again, he's the tall skinny running guy and here I am sitting beside him [laughs], so I said I don't want to sit on that bus again because it's a little intimidating. I don't care, that's wonderful all you people did that great times and continue, and you all look like a million bucks and you look so fit like the people in the magazines, but I just want to be over here on my bus with my friends just saying, "Yay! We did it, we're still upright!" You know?

In this instance, Carrie did not fit the requirements, or values, of what it meant to be a runner in her husband's group; she ran more slowly than her male peers, did not look "thin" and "fit," and was exhausted after her three and a half hour race. Such experiences in a running group may reinforce why one does not feel like a "real" runner. This quote also highlights why Carrie enjoys her running group where being a runner is not about being fast, but about the process and experience. As Shipway and colleagues (2012) discuss, Carrie's own running group is a site of positive experiences. In some cases, it takes a certain running community to affirm one's identity as a runner, particularly when using definitions divergent from the mainstream running culture. As a result, Carrie recognizes the boundary between those types of runners and herself. Carrie chooses not to challenge this by stating she would rather be on her own bus with friends celebrating the fact that she was "still upright."

For other participants, it took the recognition of the running community before they could confidently validate themselves as "real" runners. This relates back to Appiah's (2001) argument that identity can only be shaped through interactions with other people. In terms of boundaries, internal identification with a subgroup requires the recognition of those within the community and those outside the group (Lamont and Molnár 2002). Further, Wimmer (2008) notes that boundaries are also relevant based on social networks as social networks may impose a category onto someone. That imposed category may eventually be adopted as a self-identification. Kathy explains how she began to see herself as a runner, despite her speed:

You can be a little elitist just in your thinking [about being a runner] ... but, I don't really feel that way. I think it's an accomplishment, like someone who would take six hours to do a marathon is actually putting themselves out more than someone who runs it in two hours and thirty minutes. I mean, if you can commit to anything for six hours, then frankly I think that deserves an extra shirt and medal ... it was a faster runner that pointed that out to me, and I really appreciated his perspective on that ... but, thinking for myself, well, you know, "I'm not really accomplished enough compared to you," and he just turned and looked at me and said, "Are you kidding me? Like, you ran four and a half hours! I would have walked off the course if I knew it would have taken me that long, I just wouldn't do it." So, yeah, good perspective.

Moria, who recognized she was a runner after frequently visiting a local running store, expressed a similar sentiment:

I, uh, had walked into the, actually it was the [running store] and a gentleman there knew me by name because I had been there so many times to earn my running shoes and, uh, I was like you know what ... I'm a runner. He recognized me, he knows what my issues are, he knows that I am consistent, and he is acknowledging that.

In these two examples the running community helped confirm participants' experiences and identities as a "real" runner. If a new running identity can 
be accomplished, the benefits become clear. For these women, renegotiating what it means to be a runner is a vital part of feeling they are runners. It has allowed them to have more pride in their running, and to be more confident in their running abilities. When I asked these runners if they were confident in their running, they all said yes, and were excited and proud to talk about their running accomplishments. Kathy recognizes that when she began to look at herself as a runner through her own lens, and not the dominant discourse, she became a more confident runner:

I think I've come a long way on that. Um, I think I've gotten, um, I think I've gotten a lot more realistic on what I can do and can't do, and where I fit on the scheme of runners. And, and worked at making it more about myself, like it's not about anyone else, it's totally an individual sport. So if you start getting caught up in comparing yourself, then you are done.

Another benefit is that participants see themselves as positive role models for their children:

Actually, you know, I think it's as a role model for my kids too, right? 'Cause they just know, oh, it's Saturday morning, mom's running, right? They just know that ... And, um, my oldest daughter now is running, and, um, she's been texting me periodically, "Oh, I ran four miles today, or I ran 5 miles, I'm thinking of running a half marathon." ... So, um, yeah, I think it's good to be a good role model for them, and to kind of promote healthy active lifestyle. (Theresa)

Um, and they [kids] were really excited for me, like when I did my first 10k, it was on mother's day that was my mother's day celebration, and then the next year for the half marathon they were all there again, same thing ... Um, and it's been neat because we've done a couple of races together ... Um, but I'd like to think that they might be inspired to, they don't have to run, but like just to try things. You know? It can be a little bit crazy and you can try it. (Kathy)

Running is a great source of pride for these women. It is an integral part of their identity and how they view themselves and their accomplishments. Carrie brought her marathon medal and race bib to the interview. Theresa spoke of a shadow box full of her race medals, and Janet has all of her race medals hanging up in the entrance to her home. Despite participants' reservations about calling themselves runners, running is clearly an important and intrinsic part of their lives.

\section{Discussion}

What emerged from these three themes are experiences of boundaries and the difficulties of negotiating boundaries. Boundaries around being both a mother and a runner can make it difficult for the participants to put the necessary time into running longer distances, such as a marathon. Boundaries around time constraints and running make it difficult for the participants to find enough time to train. Attending to boundaries makes it clear why some women choose to complete smaller distances road races instead of marathons. Lastly, recognizing the boundaries around running subculture and choosing not to conform to the dominant running identity can lead to more positive experiences of running and a new sense of running identity.
Within the running community there are subcultures of runners that create a hierarchy of runners with "real" runners at the top and "fun runners" at the bottom. Running subcultures, in addition to the public image of runners, require one to dedicate time, energy, and additional resources to running. Running is not simply "to run," but rather a way of being; running must "become part of one's daily life. One must become a runner, one must be a runner" (Altheide and Pfuhl 1980:132). Further, Tulle (2007) suggests that running becomes something that takes importance over other aspects of everyday life. It is not enough to be a "fun runner" who occasionally runs, weather permitting (Smith 1998), but rather a "runner" is dedicated to training, improving, and completing races. In order to become this kind of runner, a "career runner," one must be emancipated from other responsibilities. My participants are not emancipated from other responsibilities and thus experience boundaries around their running and ability to be a "real" runner in the hierarchy of runners.

The boundary between being a runner and being a mother is clear in my interviews. Mothering requires the majority of the participants' time and resources and interrupts their ability to run on a regular basis or for the desired amount of time. The participants must create a division between their mothering and running. This is why the majority of them run outside of the home with a running group. It is this division between the home and a running group that allows the participants time to accomplish running goals. Participants might not call themselves a "runner" because being a mother is a more important identity to them.
Running and mothering both require the majority of one's finite resources, and all of my participants stated mothering as more important. Additionally, the participants may recognize the boundaries of being a "runner" are not compatible with being a mother, and therefore refrain from calling themselves runners. Participants that have redefined what it means to be a runner have done so to accommodate a compatible mothering identity and a running identity. Time constraints are a part of motherhood and being a proper mother. In performing proper mothering, the majority of one's resources go to mothering, and therefore little leisure time is left over for activities such as running. This is usually seen as a personal problem, and my participants have framed it as such. Participants did not address the lack of time as a broader gendered inequality within leisure itself.

The participants who do not call themselves runners may do so for various reasons. As seen above, parenting time constrains and mother guilt may prevent them from fully dedicating themselves to a running identity. Despite being recognized by the outside community as runners, they may not feel they fully embody a running identity. Researchers have studied running identity specifically, as a conceptualized "commitment" that has explicit implications for identity. If identity is a commitment, once one claims an identity, they must act accordingly (Leonard and Schmitt 1987). There are certain behaviors and roles one must fill in order to accomplish that identity. It could be that my participants do not call themselves runners because they do not want to fill the requirements of that role. Fitting the dominant running role would mean they have to 
become a disembodied runner, which is not desirable. For the women in this study, the mothering role is more important and conflicts with that runner identity.

Participants may also refrain from calling themselves a runner because they are operating under the "cloak of incompetence." Using the disclaimer of "I am not a runner; I run" relieves them of expectations that follow the label of a "runner." In considering their running, my participants recognize that there are boundaries around being a runner, and actively refrain from engaging those boundaries. For participants who choose to redefine what being a "runner" means, they, too, are choosing not to engage the boundaries that established what makes a "real" runner. Instead, they are creating their own subgroup of running that involves different boundaries and defining aspects. These boundaries may be similar to a "real" runner, such as running as a main form of exercise, but are more lenient. For example, my participants believe that being a runner is someone who runs consistently, despite speed or appearance. This definition is not only broader than a disembodied runner but also more inclusive of various runners, without relegating themselves to "joggers" at the bottom of the hierarchy.

There are still boundaries around the types of runners that my participants conceive of as appropriate. These runners, however, are still different and distinct from a "fun runner." My participants are, in fact, redistributing themselves within the hierarchy of runners. Wimmer (2008) argues that this is often done by those within boundary hierarchies as a way of recreating the boundaries of a category to allow themselves a place higher up within the hierarchy. Though my participants do not consider themselves disembodied runners, they have established themselves as having higher status than a "fun runner."

Running identity is complex, with many influencing factors. Despite the fact these women actively seek to transform what running means to them, accomplishing that transformation is dependent on many aspects, including validation from the running group, outside peers, and themselves. In some cases, the creation of new criteria for running identity may be applied to other runners, but may not be applied to oneself, like as in the cases of Theresa, Carrie, and Margaret. These three participants have redefined what it means to be a runner, but still refrain from using the running label themselves, demonstrating these newly formed running identities are still fragile, and constantly in conflict with the dominant running discourse that promotes the disembodied runner. Further research could explore how such running identities are challenged, developed, transformed, and maintained within the running community. What may be more important to further explore is why some runners subscribe to the "runner" label, while others choose not to.

Research addressing groups of runners that are often overlooked, such as middle-aged amateur females, offers insights into identity formation in instances of conflicting categories of identity. Running experiences and, by extension, running identity may be vastly different for other understudied types of runners, such as various representations of ethnicity, disability, economic class, or single parenthood. Including participants of minority or marginalized groups is just one way that researchers can continue to learn about running, identity, leisure, and the boundaries that surround these three components.

This research contributes to the growing body of literature on sport, running, and identity. Further research can be done on runners who do not fit the runner ideal (i.e., white, male, elite, and under the age of 30). This article begins to fill-in that gap by focusing on women who are middle-aged, non-elite, and mothers. It also contributes to an understanding of how identities work for and against each other, and the way that identities can be formed, rejected, and even contested. Understanding running identity, mother guilt, and time constraints can also be used to understand the continued gender gap in road racing-my original research question.

Beyond sport and leisure this work on boundaries and identity could be extended to other areas, including boundaries between identities of parenthood and leisure generally, but also identities pertinent to the work role, parenthood, and other master statuses. Whichever research questions may arise, the results of my interviews are just one stepping stone to understanding the world of leisure, mothering, sport, boundaries, and identity.

\section{References}

Abbas, Andrea. 2004. “The Embodiment of Class, Gender, and Age Through Leisure: A Realist Analysis of Long Distance Running." Leisure Studies 23(2):159-175.

Acker, Joan. 1990. “Hierarchies, Jobs, Bodies: A Theory of Gendered Organizations." Gender and Society 4(2):139-158.

Altheide, David and Erdwin Pfuhl Jr. 1980. "Self Accomplishment Through Running." Symbolic Interaction 3(2):127144.

Appiah, Kwame. 2001. “Liberalism, Individuality, and Identity." Critical Inquiry 27(2):305-332.

Berg, Bruce. 2009. Qualitative Research Methods: For the Social Sciences. Boston, MA: Pearson Education.
Bittman, Michael. 1998. "Land of the Lost Long WeekendTrends in Free Time Among Working Age Australians 19721992." Society and Leisure 21:353-378.

Bittman, Michael. 2004. "Parenting and Employment: What Time-Use Surveys Show." Pp. 152-170 in Family Time: The Social Organization of Care, edited by Nancy Folbre and Michael Bittman. New York: Routledge.

Bittman, Michael and Judy Wajcman. 2004. “The Rush Hour: The Character of Leisure Time and Gender Equity." Pp 174-194 in Family Time: The Social Organization of Care, edited by Nancy Folbre and Michael Bittman. New York: Routledge.

Boeije, Hennie. 2010. Analysis in Qualitative Research. Thousand Oaks, CA: Sage. 
Choi, Precilla. 2000. Femininity and the Physically Active Woman. London: Routledge.

Collinson, Jacqueline and John Hockey. 2007. “Working Out Identity': Distance Runners and the Management of Disrupted Identity." Leisure Studies 26(4):381-398.

Corbin-Dwyer, Sonya and Jennifer Buckle. 2009. “The Space Between: On Being an Insider-Outsider in Qualitative Research." International Journal of Qualitative Methods 8(1):54-64.

Dowling, Colette. 2000. The Frailty Myth: Redefining the Physical Potential of Women and Girls. New York: Random House.

Gershuny, Jonathan I. 2000. Changing Times: Work and Leisure in Post-Industrial Society. Oxford: Oxford University Press.

Gimenez-Nadal, Jose and Almudena Sevilla-Sanz. 2011. "The Time-Crunch Paradox." Soc Indic Res 102:181-196.

Griffith, Alison and Dorothy Smith. 2005. Mothering for Schooling. New York: Routledge.

Heisler, Jennifer and Jennifer Butler-Ellis. 2008 “"Motherhood and the Construction of 'Mommy Identity': Messages About Motherhood and Face Negotiation." Communication Quarterly 56(4):445-467.

Hochschild, Arlie and Anne Machung A. 1989. The Second Shift. New York: Penguin Group

utel, Annemarie. 2003. “'Thou Dost Run as in Flotation': Femininity, Reassurance, and the Emergence of the Women's Marathon." International Journal of the History of Sport 20(3):17-36.

Kanuha, Valli K. 2000. “'Being' Native Versus 'Going Native': Conducting Social Work Research as an Insider." Social Work 45(5):439-447.

Kay, Tess. 2003. "Leisure, Gender, and Self in the Analysis of Family." World Leisure 4:4-15.

Lamont, Michèle and Vigár Molnár. 2002. "The Study of Boundaries in the Social Sciences." Annual Review of Sociology 28:167-195
Leonard II, Wilbert and Raymond Schmitt. 1987. "Sport-Identity as Side Bet-Towards Explaining Commitment From an Interactionist Perspective." Intern Sport 22:249-262.

Lynch, Chris. 2010. Doing Your Research Project in Sport. Exeter Learning Matters.

Mattingly, Marybeth and Suzanne Bianchi. 2003. "Gender Differences in Quantity and Quality of Free Time: The U.S. Experience." Social Forces 81(3):999-1030

Mattingly, Marybeth and Liana Sayer. 2006. “Under Pressure Gender Differences in the Relationship Between Free Time an Feeling Rushed." Journal of Marriage and Family 68:205-221.

McLuhan, Arthur et al. 2014. “Cloak of Incompetence: An Exploration and Research Agenda." Paper presented at the 31 annual Qualitatives Conference, June 25, London, Canada.

Ogles, Benjamin and Kevin Masters. 2003. "A Typology of Marathon Runners Based on Cluster Analysis of Motivations." Journal of Sport Behavior 26(1):69-85.

Patel, Russell and Jennifer O'Neill. 2007. “American Women in the Marathon." Sports Medicine 37(4/5):294-298.

Runningusa.org. 2014a. "Running USA's Annual Half Marathon Report." Retrieved June 04, 2015 (runningusa.org).

Runningusa.org. 2014b. “Running USA's Annual Marathon Report.” Retrieved June 04, 2015 (runningusa.org).

Sayer, Liana. 2005. "Gender, Time, and Inequality: Trends in Women's and Men's Paid Work, Unpaid Work, and Free Time." Social Forces 84(1):285-304.

Shipway, Richard, Immy Holloway, and Ian Jones. 2012. “Organization, Practices, Actors, and Events: Exploring Inside the Distance Running Social World." International Review for the Sociology of Sport 48(3):259-276.

Smith, Stuart. 1998. "Athletes, Runners, and Joggers: Partic pant-Group Dynamics in a Sport of 'Individuals."' Sociology of Sport Journal 15:174-192.
Tulle, Emmanuelle. 2007. "Running to Run: Embodiment, Structure, and Agency Amongst Veteran Elite Runners." Sociology 41(2):329-346.

Vryan, Kevin, Patricia Adler, and Peter Adler. 2003. "Identity." Pp. 367-390 in The Handbook of Social Interactions, edited by
West, Candace and Don Zimmerman. 2007. "Doing Gender." Pp 61-72 in Gender Relations in Global Perspective: Essential Readings, edited by Nancy Cook. Toronto: Canadian Scholars Press.

Wimmer, Andreas. 2008. “The Making and Unmaking of Ethnic Boundaries: A Multilevel Process Theory." American Journal of Sociology 113(4):970-1022. 